\title{
Immersive Environments - A Connectivist Approach
}

\author{
Ana Loureiro and Teresa Bettencourt \\ CIDTFF (Research Center for Didactics and Technology in Teacher Education) / \\ Department of Education / University of Aveiro \\ Aveiro / Portugal \\ Higher School of Education / Polytechnics Institute of Santarém \\ Santarém / Portugal \\ accloureiro@gmail.com \\ CIDTFF (Research Center for Didactics and Technology in Teacher Education) / \\ Department of Education / University of Aveiro \\ Aveiro / Portugal \\ tbett@ua.pt
}

\begin{abstract}
We are conducting a research project with the aim of achieving better and more efficient ways to facilitate teaching and learning in Higher Level Education. We have chosen virtual environments, with particular emphasis to Second Life ${ }^{\circledR}$ platform augmented by web 2.0 tools, to develop the study. The Second Life ${ }^{\circledR}$ environment has some interesting characteristics that captured our attention, it is immersive; it is a real world simulator; it is a social network; it allows real time communication, cooperation, collaboration and interaction; it is a safe and controlled environment. We specifically chose tools from web 2.0 that enable sharing and collaborative way of learning. Through understanding the characteristics of this learning environment, we believe that immersive learning along with other virtual tools can be integrated in today's pedagogical practices.

However, before we can apply and suggest best practices we need to get to know the virtual environments we intend to use (2D and 3D). We must characterize and understand how interactions and relationships are established, in particularly, between the users of this Multi-User Virtual Environment. We have made preliminary observations of residents' behaviour at Second Life ${ }^{\circledR}$, including some informal or natural learning contexts. Our analysis of those observations led strongly to theory of Connectivism approach, which is defined as a learning theory for the digital age.

This paper will present the outlined research and a literature review about the Connectivism theory and its application to the virtual environments.
\end{abstract}

Keywords: Connectivism, connective knowledge, e-learning 2.0, learning contexts, virtual environments, web 2.0.

\section{Introduction}

We are living in the era of the networked society; networks include and organize the essential of our richness, knowledge, power, communication, technology [23] and 
therefore the way we learn. Every day and pretty much along our whole day we have a close contact with various forms of technology. We all carry gadgets that allow us to keep in touch with this "world of fast context-switching" [1] where we live. No matter if we use them to communicate, cooperate, interact, work, share or learn. Whether 'digital natives' or 'digital immigrants' [4].

Technologies and networks are a reality and they are available for almost everyone. Education cannot ignore this evolution and must be aware of the new demands that arise with the connected society. As Brandão said "it is broadly recognised that the role of teacher is changing and the new teaching methodologies must be implemented in the classroom and in the school projects, creating favourable environments for pupils and teachers to fully benefit from information and communication technologies. Teachers will have to promote key skills such as collaborative working, creativity, multidisciplinarity, adaptiveness, intercultural communication and problem-solving among themselves and transfer to pupils" [25]. Although, and in many situations, what we see is not an evolution but a stagnation of the ways of delivering teaching. Old approaches remain, and more often than not "students are asked to sit in rows and listen to lectures, take notes or solve exercises given by teachers. It's a teaching strategy that doesn't prepare students to be critical citizens and professional workers on their specialty, nor give them the skills and competences needed to be autonomous and constructors of knowledge" [2]. In fact it seems students of this networked society "have limited patience with an educational system that has not changed substantially since the 19th century. They think and learn in environments that are fast-paced, multimedia, multimodal, interactive, and, of course, digital. These volatile, interconnected, and complex social milieus (Cohill, 2000) call for learning options that are critical, collaborative, creative, and futures oriented" [3].

Today's students are interconnected, living in a digital age, multiprocessing and multitasking. The Web is now not only an informational and social resource, but also a learning tool that enables new ways of creating and sharing knowledge. With today's networked society we can observe a new way of learning that is discovery based. Education cannot ignore those changes, cannot cling to the old habits and methods of teaching and learning from the last century. As Prensky said "our students have changed radically. Today's students are no longer the people our educational system was designed to teach" [4].

Some people tend to think that "kids who are multiprocessing can't be concentrating. (...) the attention span of the teens at PARC-often between 30 seconds and five minutes-parallels that of top managers, (...) the short attention spans of today's kids may turn out to be far from dysfunctional for future work worlds" [1]. Consequently teachers are becoming challenged to develop new strategies in order to fulfil the needs and enhance the skills of their digital age students; to achieve better ways of capturing and maintaining students' attention.

We believe that we can only engage our students' attention and motivation if we leverage the same tools. By getting to know their digital and immersive worlds; and becoming part of it. Teaching students in new ways is critical for creativity and innovation to evolve. Web 2.0 tools are a way to reach digital natives, a way to connect with them and to catch and maintain their attention and motivation, particularly through games and other virtual 3D environments. 
Today's students have a close contact with a huge number of digital tools, creating, changing, rebuilding, and updating their profiles and their knowledge. They establish a network of connections that enables "Involve, Create, Discuss, Promote, Measure" [5] information and knowledge. It is now understood that information and knowledge are no longer for life nor in possession of a handful of eminent thinkers. It is public and it changes rapidly. It is now possible for everyone to build, share, acquire and innovate through the social Web, using the facilities and the potential of Web 2.0. These tools are available from any space and time, they are user friendly and with free access. New contents in different contexts grow, allowing a "connective knowledge" [6] between networked users. We have what we can call as a "learnovation" society. In fact, as Siemens refers, "the capacity to form connections between sources of information, and thereby create useful information patterns, is required to learn in our knowledge economy", and "connections that enable us to learn more are more important than our current state of knowing" [7].

In the follow section we will present and characterize our ongoing study. We will also present the learning theory that we find as being the best one for supporting the study.

\section{The Study}

We are conducting a research study that is being developed as part of a Doctoral Program in Multimedia in Education at the University of Aveiro, under the name Knowledge Building in Virtual Environments - Influence of Interpersonal Relationships. The study will be conducted in the tridimensional virtual environment called Second Life® (SL®) and with the support of Web 2.0 tools (like Diigo and Facebook).

Before we chose the 3D environment we explored others like Activeworlds, BlueMars, IMVU, MOOVE, There. We asked students for some cooperation in this task, asking them to select their favorite environment and why. The elected one was SL®. Second Life® itself as many of other "virtual worlds are not themselves games" [8]. Second Life $®$ is a free to use 3D multi-user virtual environment, it is immersive, and it is imagined, designed, built and created by its residents (avatars). Second Life $®$ is a playground for our imagination, a limitless platform - design, build, code, perform and collaborate, expanding the boundaries of creativity. It is a real life simulator, allowing all sorts of experiences and studies (from every field of science, humanities and art), all in a safe and controlled environment.

Multi-user virtual environments (MUVE), with special emphasis on SL® have been used in an education context. Actually some of the major universities all over the world have a virtual representation/campus at Second Life ${ }^{\circ}$ ( $c f$. http://secondlife.com/whatis/destinationguide/category.php?c=learning).

We perceived that we could learn in, with and from virtual environments. MUVE allows learning "through exploring environments, 'realia', lived and virtual experiences with tutorial and peer-based support" [9]. These environments make students feel more confident, more open, more participative, more creative, and more responsive. In fact, in the immersive virtual environments, students seem to attend training sessions because they want to learn. Students actually can interact with the simulated world "allowing them to engage with content (Bricken, 1991). Being able to learn 
subject matter in the first person, as opposed to the third person" which is "experiential, nonsymbolic, interactive, and multisensory" [3].

To contextualise this study we can refer that this research emerged from the need to "observe some of the variables that have been already identified by Bettencourt' (aka Bekkers) study (2009) and give it continuity" [10]. These variables are related with three major areas: the person and their motivations; the relationships that exist or are established between avatars or between avatars and persons; and finally the social integration in Second Life $®$ (by which we mean sense of community). We define avatar as "a digital persona that we can create and customize, it is our virtual 3D representation" [22]. Although the three main areas are related and can't be observed independently since they all are interconnected and influence one another. Our research concerns are more focused on learning relationships that are established in real life and then flow into a virtual environment and then flow back into real life again, we are looking to establish whether this flow is complementary.

We are observing in world teachers and learners in a formal context of learning and in an informal - or natural - context of learning. These teachers and learners represent our research sample - picked up among the Portuguese universities and polytechnics population. This is an intentional sample, non probabilistic type.

The researcher (and teacher), is working with a target group of students (a regular class and an adult class, both Higher education students). Both sets of students are from an Education and Multimedia Communication Course. Each group of students was given a research challenge, their performance in this task was use to evaluate the effectiveness of Second Life $® /$ Diigo in promoting collaboration, communication and interaction skills. Prior to work commencing, the students were asked to select a virtual environment that could host students/teacher meetings. After a class discussion about the advantages and disadvantages of some virtual environments (2D and 3D), one was selected - Second Life ${ }^{\circledR}$. Most of the students had no prior experience of Second Life ${ }^{\circledR}$. The main goal was to help students to understand the importance of sharing information and discuss contents in an open place. The teacher only meets each class (in a formal way) once a week. The teacher also has some hours of contact out of the classroom (support hours). These hours suit the regular students but don't meet the adult students' needs (since they are part time, and have full-time jobs). The only way we found to give an extra support to the adult class was through a virtual environment. We discovered there were further opportunities for enrichment to everyone by encouraging the regular students to join the virtual tutorials. The teaching methodology uses the physical classroom hours to develop and work through practical content. The virtual classroom is being used to work and discuss around the theoretical content of the subject (using both Diigo - http://groups.diigo.com/group/lah2010 and Second Life $\left.{ }^{\circledR}\right)$. None of these spaces is closed to the community. Anyone can join us and contribute to the discussion and content sharing. We are working under the missive "I store my knowledge in my friends" [18]. If one of us does not know something we just check it with a friend. The students are connected to the network through other Web 2.0 tools (Facebook, HI5, Digg, LinkedIn, Plaxo, Twitter, several blogs), using the connections they establish in there to enrich the contents and discussions around the class topics. The virtual meetings in Second Life ${ }^{\circledR}$ happen at the Academia Portucalis ( $c f$. http://slurl.com/secondlife/Portucalis/218/167/22). The choice of this location was left for the students to decide, (the other option was the 
official Higher School Island - SLESES). We should mention, at this point, that this tutorial methodology is not an obligation for students. They are cooperating with this task and in the virtual meetings of their own free will. We show an example of a virtual meeting ( $c f$. Fig. 1). We are applying a pedagogical philosophy of learning where the knowledge is built by students [24].

The teacher is no longer the center of the knowledge; the role has evolved to being a guide, a facilitator. Helping students to search, select, relate, analyze, synthesize and apply information and therefore build knowledge. Teacher's role changed from formal into informal and collaborative. Teacher is there available (sharing and using the same virtual environments), motivating, promoting team work, cooperative learning and dialogue, stimulating the intellectual accuracy and facilitating student's autonomy in their search for knowledge and understanding. The teacher becomes a mentor for students in a more reflective learning context.

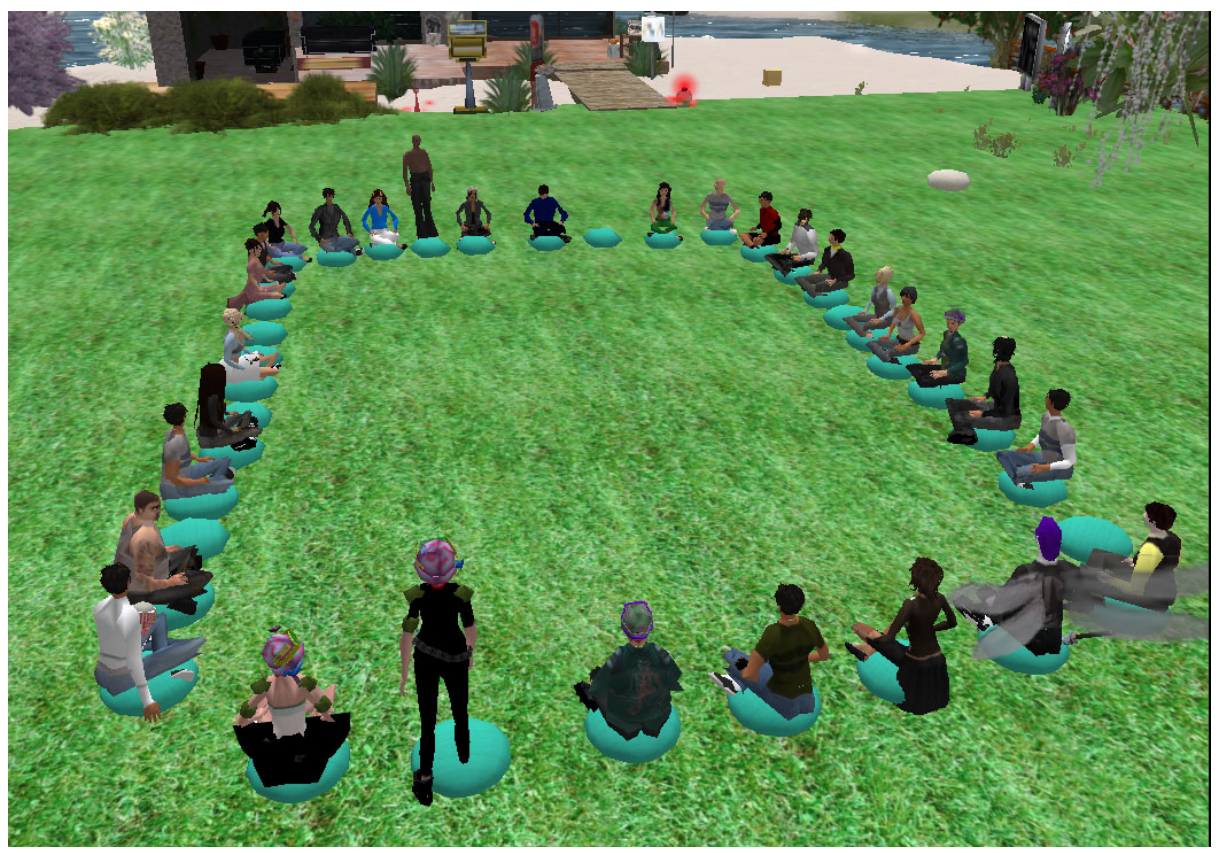

Fig. 1. Virtual meeting in Second Life ${ }^{\circledR}$

It is an exploratory and qualitative study. We intend to use surveys (with closed answers) to inquire about the reasons why people enter into Second Life $₫$ and also what kind of difficulties they experience in using the environment; if they felt curiosity about exploring the environment; what kind of activities are they doing, where and how long; what is the frequency of logging in and how many hours they stay logged in. We also intend to make some interviews when, and if, we feel need of an additional information, or a clarification / explanation about some of the collected data. Besides these two instruments we also will be working, and mostly, as observers, to identify key indicators (such as the avatar appearance and how the avatar behaves 
when in a group or community), that will help us to clarify the level of growth or socialization of the avatar / person in the virtual environment of Second Life .

The main goals of our research are:

- understand in which way the interpersonal knowledge in real life can combine with the personal development/grow in virtual worlds - in particular Second Life $\AA$, and in this way achieve insights to a better understanding of the way knowledge is built in virtual worlds optimizing is use and then transfer it to real life contexts of learning - with an impact in the traditional classrooms;

- $\quad$ analyse the several contexts of users logging in and identify the reasons for them to stay, how they grow, what they experience in Second Life ${ }$.

We will try to understand the major differences of behavior between people who come to Second Life ${ }^{\circledR}$ by free will and the ones who were required to join the environment. We intended to provide some "insights for all educators and researchers interested in using those environments as a teaching medium in real life, and propose new approaches to better prepare the university students for the marketplace that will emerge" [2], as well as to achieve a better understanding of how people grow and build knowledge in Second Life ${ }^{\circledR}$ in both formal and informal or natural learning contexts. And like in everything we believe informal or natural context is the one that seems more valuable.

To achieve those goals we set our research questions along the following themes:

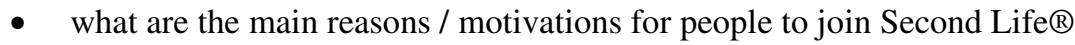

- $\quad$ what are the main factors for them to stay and play in Second Life ${ }^{\circledR}$

- $\quad$ what are their personal paths of development/growth in Second Life®

- $\quad$ and in what way interpersonal knowledge cycling around real world and virtual world.

We expect this study to achieve improved understanding and better knowledge about immersive learning in order develop best practices for teaching and learning strategies in virtual environments. Subsequently, we will transfer that knowledge to real life learning contexts and in this way provide best approaches for teaching and learning in a higher level.

After a careful comparison with learning theories more often used to define and characterise learning contexts and learning environments we have concluded that Connectivism theory is the best one to support this particularly study.

In the next section we will drew some insights about Connectivism and connective knowledge, presenting a literature review about these two topics.

\section{Connectivism and Connective Knowledge}

Connectivism is described as being the learning theory for the digital age. As Siemens said the theories most often used to describe the learning process (Behaviorism, Cognitivism and Constructivism) do not preview in their outlines the way learning is impacted by technology, which is something that we cannot ignore in digital age. More often than not, technology "has reorganized how we live, how we communicate, 
and how we learn" [7], there so learning theories of the new age should be reflective and with a glance at social environments, since learning (especially in its informal and natural form) often is widely influence by it. Other ways of achieving and reaching learning have arisen, due to social networks and the types of connections that the World Wide Web allows. As Vaill said, referred by Siemens, "learning must be a way of being - an ongoing set of attitudes and actions by individuals and groups" [11]. It is important to refer that we perceive learning as a "lifelong process of transforming information and experience into knowledge, skills, behaviors, and attitudes" [12]. To learn is to "acquire certain patterns" [13]. It is also the result of interactions and connections that we establish with fellows of our community, peers, personal or social networks. In this way; "to know something is to be organised in a certain way, to exhibit patterns of connectivity" [13]. Connectivism learning theory states that "knowledge - and therefore the learning of knowledge - is distributive, that is, not located in any given place (and therefore not 'transferred' or 'transacted' per se) but rather consists of the network of connections formed from experience and interactions with knowing community" [13]. In a digital society, as the one we live, connections and networks are a reality, as the links that are established between users are. The Web's users are no longer simple information collectors (Web 1.0), they are active and reactive users, developing and sharing content and information, influencing the build of knowledge of the other users. Each one of us has an intrinsic need of being part of cyberspace, of being known by our partners, an unfulfilled eagerness for communication, and to share our thoughts, needs and knowledge. We are now swimming in the "real time, co-creative Web" [20]. We all are now content builders, information sharers, communicators. We all belong to a common space with no barriers, made of links, nodes and connections. Every day we establish new contacts, increasing our networks, sharing and collecting new information, rebuilding our knowledge, and learning.

At this point we can take a close look to the most considerable directions of learning in a digital interconnect society, according with Siemens [7]:

- More often than likely we move into a variety of different and probably unrelated areas of knowledge over our life time;

- We learn walking around through several chains of our life, such as communities of practice, social and personal networks, and while we develop "work-related tasks";

- We cannot separate learning and work activities anymore, since they are in many situations related. We are in continuously learning process, life-long learning;

- Our brains, somehow, are being shifting by technology since "the tools we use define and shape our thinking";

- A theory that explain the links that are established between "individual and organizational learning" is needed since they both are learning organisms;

- Technology can now support and deliver many of the learning processes (no matter if using the informal tools of Web 2.0 or a MUVE, if using a formal platform - LMS, PLE);

- More important than know-how and know-what, is to know "where to find knowledge needed". 
Bessenyei supports this by stating that "the motivation for gaining and contextualising information becomes stronger if searching and evaluation becomes a cooperative, network activity. Students can significantly improve the efficiency of their learning if they take part in a network, or virtual community dealing with the given subject. Thus the collective knowledge once again becomes a source of individual knowledge ('cycle of knowledge development'). As the number of cooperative activities increases, personal social networks become the scene of informal exchange of expertise, and 'communities of practice' develop. Besides the questions of 'how' and 'what' to learn, we now have the question of "where to learn"” [14].

Connectivism is "the integration of principles explored by chaos, network, and complexity and self-organization theories" [7]. It puts the emphasis of enable students with skills to search for, filter, analyze and synthesize information that they gather while exploring networks in order to achieve knowledge. This aspect gets importance every time information or knowledge "is needed, but not known, the ability to plug into sources to meet the requirements becomes a vital skill. As knowledge continues to grow and evolve, access to what is needed is more important than what the learner currently possesses" [7].

Knowledge has two dimensions, explicit and tacit ones. According with Brown, "explicit dimension deals with concepts - the 'know-what' - whereas the tacit deals with 'know-how', which is best manifested in work practices and skills. Since the tacit lives in action, it comes alive in and through doing things, in participation with each other in the world. As a consequence, tacit knowledge can be distributed among people as a shared understanding that emerges from working together" [1].

Connectivism is based in the assumption that decisions are made under conditions that change fast allowing new information to continually be acquired. For this reason the capacity to distinguish and select what is important becomes essential, and there so the capacity to recognise when the new information alters what we previously known, reshaping the knowledge, rebuilding the learning.

Connectivism main assumptions are [7]:

- $\quad$ "Learning and knowledge rests in diversity of opinions.

- Learning is a process of connecting specialized nodes or information sources.

- Learning may reside in non-human appliances.

- Capacity to know more is more critical than what is currently known

- Nurturing and maintaining connections is needed to facilitate continual learning.

- Ability to see connections between fields, ideas, and concepts is a core skill.

- Currency (accurate, up-to-date knowledge) is the intent of all connectivist learning activities.

- Decision-making is itself a learning process. Choosing what to learn and the meaning of incoming information is seen through the lens of a shifting reality. While there is a right answer now, it may be wrong tomorrow due to alterations in the information climate affecting the decision".

In the next section of the paper we will relate Connectivism and Second Life® and how this learning theory can be applied into learning contexts that are developed and build in this virtual environment. 


\section{Connectivism and Immersive Worlds}

As Siemens observed, the major learning theories do not take into account the impact of technology. In fact, these major theories (Behaviorism, Cognitivism and Constructivism) do not relate, or explore, the concept of learning that occurs outside of a person. With technology much of the information, and therefore learning and knowledge, is stored and manipulated by technology. Connectivism intends to fulfil a gap in learning theory, delivering a one that is based in the "impact of technology and new sciences (chaos and networks) on learning" [7]. Nowadays people store pretty much everything in networks, depending of technology for their daily lives. We work, learn, socialize, and interact through technologies.

Second Life ${ }^{\circledR}$ is an online immersive 3D multi-user virtual environment, where each user (or resident, as they are called) is able to have a life that can simulate the real life in almost every aspects (adding some other features that humans can't do at real life) and it is represented in world by his/her avatar. In fact, and according to Linden Lab® itself, "Second Life is a virtual world that allows its residents to create completely original content using atomistic building tools in a shared and globally accessible space" [15].

As we previous stated we believe that Second Life ${ }^{\circledR}$, having itself MUVE's (Multi-User Virtual Environment) characteristics, have great possibilities if used for education and learning purposes. This environment is like an "ever growing virtual playground that is limited only by the creativity of its users" [16]. According with Federation of American Scientists it will allow us "to build 3-D objects collaboratively and in real time with others in the same world" [17], with major applications at "building, design, and art principles". On the other hand, Second Life ${ }^{\circ}$, is a "rough simulation of the natural world, with meteorological and gravitational systems, the possibilities of experimenting with natural and physical sciences are endless"[17], and all this "in a safe and controlled environment" [17]. The twist is that in an immersive environment we are walking inside the material, not just viewing it from a distance. In fact, Second Life ${ }^{\circledR}$ and other MUVEs "have attracted a growing and increasingly sophisticated community of practice (Wenger, 1998) focused on the topic of teaching and learning in 3D immersive worlds" [3].

SL® is not designed primarily as an educative tool, however, as previously indicated, it can be used in several learning contexts. Second Life ${ }^{\circledR}$ seems to be a good option to emulate a virtual classroom. To facilitate a more effective learning environment $\mathrm{SL} \circledast$ requires augmentation through adding tools that enable, for instance, students' and teachers' content sharing. The combination of the tools will connect students to the network and to the links of information. Each virtual environment has its role and importance in the knowledge building.

SL® as a learning platform reflects the assumptions of the Connectivism theory in many ways. We know nowadays that information and knowledge are transitory, chaotic and unstable, there is an inherent need of a continuous learning (life-long learning). SL® enables a contact and connection with a diversity of opinions, nodes, links and specialized information sources. Because it is digital, virtual and immersive it allows those information links to be more interactive, which enhances the learning and information sharing. It is an endless network of links allowing contacts to flow in between virtual platforms (2D, 3D) and real life. 
On the other hand, the motivation, feelings and sense of community belonging that are generated among SL® users helps to create, develop and maintain connections, and facilitates a process of continuous and natural learning. The environment has available a huge number of communities and groups, according with likes, needs, interests. It is easy to find a group with who we feel affinity for one or other reason. Inside these groups or communities relationships are established and information flows. Members build and share, becoming content providers themselves.

Connections are made and the network of relationships grows and gets enforced progressively. The bonds that are created between the members in many situations jump the borders of the 3D environment. They are enforced outside through a $2 \mathrm{D}$ platform or even at real life. Connections are like a snowball effect. The individual network is made of, or complemented, with their friends' networks. As Stephenson said "I store my knowledge in my friends" [18]. In this digital age we have a network of connections that is made of links and nodes with people. It is a "collective knowledge through collecting people" [18]. Actually most people know an 'expert' who they can go to, and that is the power of a network, all contributing expertise. Once again we go into the premise of Connectivism "Know-how and know-what is being supplemented with know-where (the understanding of where to find knowledge needed)" [7]. Internet provides new ways of making those connections, provides an extra dimension of collaborative sharing. Knowledge is "distributed, because it is spread across more than one entity. A property of one entity must lead to or become a property of another entity in order for them to be considered connected; the knowledge that results from such connections is connective knowledge" [6].

Knowledge management is about maintaining the nodes (a node is a knowledge base plus human interpretation), adding fresh ideas, removing outdated knowledge, rebuilding perceptions and therefore learning. And again ability to "know more is more critical than what is currently known". Virtual environments, like SL®, can be an endless network of connections, or relationships, where knowledge can be distributed across a community of people.

The establishment of ties and bonds between people are required since "to learn is to immerse oneself in the network" [13]. In a virtual environment, in theory, there are no barriers or borders, and information flows, people build and share content, relationships are set up, the net of connections extends and we achieve knowledge. This acquisition is made in a natural way, by participating in a community, by sharing, discussing and launching ideas, contents and information, therefore a "learning activity is (...) a conversation undertaken between the learner and the other members of the community" [13]. It is a natural process of interaction and reflection with the guidance and correction of expertises or peers.

Second Life, as a natural and informal virtual environment, can be used for the set of e-learning 2.0 contexts. Downes defines e-learning 2.0 as being "an approach to learning that is based on conversation and interaction, on sharing, creation and participation, on learning not as a separate activity, but rather, as embedded in meaningful activities such as games or workflows" [13]. In the virtual 3D environments we can do everything we just described. Actually, these immersive environments "bridges the gap, so people live the experience, live the learning, and thereby learn better" [10]. For us these are alternative methods of presenting content, as an attempt to catch and maintain student's attention. In fact immersive worlds have a huge potential for education because they can facilitate "collaborations, community and experiential learning" [19]. 


\section{Conclusion}

In this paper we set out to share some of the literature review that we are outlining currently, related with the learning theory of Connectivism and its relation with immersive virtual environments.

As we have mentioned previously we expect, with this research, to achieve a better knowledge about immersive learning and therefore transfer that knowledge to real life learning contexts and in this way provide best approaches for teaching and learning in a Higher level. Immersive environments seem to facilitate the development of elearning 2.0 situations specifically because it stimulates teachers' innovation of their practices and leads them into a collaborative approach with students. Teachers and students become partners and interact socially to a common goal. The process of teaching and learning tend to be more focused on the development of skills: critical thinking, making initiatives, entrepreneurship, responsibility, teamwork, respect for others and their differences, inter-culturality" [2]. We tend to agree with Wagner when he refers that MUVEs are "an ideal pedagogical resource" [17], special because, "acting in virtual communities is nothing new to homo zappiens and is part of normal life" [21], actually, in this digital age and for the most common users "both real and virtual life are components of their lives, without considering one less valuable or real than the other" [21].

The immersive virtual environments, based on its characteristics, favour the social interactions and the creation of links, connections and nodes. These are the basis for knowledge building, and therefore for learning. Fundamentally, this is what Connectivism is all about: establishing personal and social networks. In these networks a natural learning context emerges, a natural way of seeking knowledge. Digital students have a whole net of connections and relationships, real and virtual ones. Virtual environments tend to facilitate the contacts, tend to favour the person's emancipation. Everyone can access to information and therefore transform it into knowledge, through conversations and interactions with others. Since virtual immersive worlds, like Second Life ${ }^{\circledR}$ are by its nature informal environments, access to knowledge becomes also natural and an easiest process. If we add to it the other tools we can use at web 2.0 and the connections we establish there, then we can have a huge network of connections, links and nodes and knowledge building achieve a whole new dimension. In a networked society the knowledge is build by students (with teachers' guidance) and learning becomes a process of social nature.

\section{References}

[1] Brown, J.: Growing up digital (2002),

http: / /www.usdla.org/html/journal/FEB02_Issue/article01.html (retrieved February 26, 2009)

[2] Bettencourt, T.: Teaching \& Learning in SL: Figuring Out Some Variables (2009), http: / / cleobekkers. wordpress.com/2009/01/28/ teaching-learning-in-sl-figuring-out-some-variables/ (retrieved January 30, 2009) 
[3] Richter, J., Inman, L., Frisbee, M.: Critical engagement of teachers in Second Life®: progress in the SaLamander Project. In: Livingstone, D., Kemp, J. (org.) Pro-ceedings of the Second Life ${ }^{\circledR}$ Education Workshop 2007 - Part of the Second Life ${ }^{\circledR}$ Community Convention, pp. 19-26 (2007),

http://www.simteach.com/slccedu07proceedings.pdf (retrieved January 20, 2009)

[4] Prensky, M.: Digital Natives, Digital Immigrants (2001), http: / /www. marcprensky.com/writing/Prensky\%20-\%20Digital $\% 20$ Natives, $\% 20$ Digital $\% 20$ Immigrant $5 \% 20-\% 20$ Part $1 . p d f$ (retrieved January 25, 2010)

[5] Hayes, G., Papworth, L.: The Future of Social Media Entertainment (2008), http: / /www personalizemedia.com/the-future-of-social-mediaentertainment-slides / (retrieved January 25, 2010)

[6] Downes, S.: An Introduction to Connective Knowledge (2007), http://www.downes.ca/files/connective_knowledge.doc (retrieved January 25, 2010)

[7] Siemens, G.,, C.: A Learning Theory for the Digital Age (2004), http://www.elearnspace.org/Articles/connectivism.htm (retrieved February 26, 2009)

[8] Austin, T., Boulder, C.: The Horizon Report, 2007. New Media Consortium and EDUCAUSE Learning Initiative (2007), http://www.nmc.org/pdf/ 2007_Horizon_Report.pdf (retrieved January 26, 2009)

[9] Freitas, S.: Learning in Immersive Worlds (2006), http: / /www.jisc.ac.uk/media/documents/programmes/elearningin novation/gamingreport_v3.pdf (retrieved February 26, 2009)

[10] Loureiro, A., Bettencourt, T.: Building Knowledge in the Virtual World - Influ-ence of Real Life Relationships. In: Boa-Ventura, A., Morgado, L. e Zagalo, N. (org.) Proceedings of the SLACTIONS 2009 - Research Conference in the Second Life® World (2009)

[11] Vaill, P.: Learning as a Way of Being. Jossey-Blass Inc., San Francisco (1996)

[12] Cobb, J.: A Definition of Learning (2009), http: / /www.missiontolearn.com/2009/05/ definition-of-learning/ (retrieved January 25, 2010)

[13] Downes, S.: Learning Networks and Connective Knowledge (2009), http: / /www. downes. ca/post/36031 (retrieved January 25, 2010)

[14] Bessenyei, I.: Learning and Teaching in the Information Society. E-learning 2.0 and Connectivism (2007),

http://www.ittk.hu/netis/doc/ISCB_eng/12_Bessenyei_final.pdf (retrieved January 25, 2010)

[15] Lester, J.: Artistic expressions in Second Life. Journal of Virtual Worlds Re-search (2009), http: / / jvwresearch.org/v1n3 . html (retrieved March 20, 2009)

[16] Johnson, N.: The Educational Potential of Second Life® (2006), http://digitalunion.osu.edu/showcase/virtualenvironments (retrieved February 2, 2008)

[17] Wagner, J.: The School of Second Life®: Creating new avenues of pedagogy in a virtual world (2007) http: / /www . edutopia.org/school-second-life (retrieved February 1, 2008)

[18] Stephenson, K.: What Knowledge tears apart, networks make whole. International Communication Focus, 36 (1998), http://www.netform.com/html/icf.pdf (retrieved January 25, 2010) 
[19] Kemp, J., Livingstone, D.: Putting a Second Life ${ }^{\circledR}$ "Metaverse" Skin on Learning Management Systems (2007), http://www.sloodle.org/whitepaper.pdf (retrieved February 2, 2008)

[20] Hayes, G.: Virtual Worlds, Web 3.0 and Portable Profiles (2006), http: / / www.personalizemedia.com/

virtual-worlds-web-30-and-portable-profiles (retrieved February 2, 2008)

[21] Veen, W., Vrakking, B.: Homo Zappiens - Growing up in a digital age. Network Continuum Education, London (2006)

[22] Loureiro, A., Bettencourt, T.: The use of Immersive worlds for learning contexts: - A Connectivism Approach. In: Proceedings of the INTED 2010 International Technology, Education and Development Conference, pp. 002459- 002467 (2010)

[23] Castells, M.: A sociedade em rede. In: Cardoso, G., et al. (eds.) A sociedade em rede em Portugal, pp. 19-29. Campo das Letras, Porto (2005)

[24] Lima, J., Capitão, Z.: E-Learning e e-Conteúdos - Aplicações das teorias tradicionais e modernas de ensino e aprendizagem à organização e estruturação de e-cursos. Centro Atlântico, Lisboa (2003)

[25] Dias, P., Gonçalves, A.: PICTTE: um projecto de formação a distância para professores. In: Dias, P., e Freitas, C. (org.) Proceedings of II Conferência Internacional de Tecnologias de Informação e Comunicação na Educação, Challenges', pp. 301-312. Centro de Competência Nónio Século XXI, Universidade do Minho, Braga (2001) 